\title{
Optimal Trajectory Tracking Control for a Wheeled Mobile Robot Using Fractional Order PID Controller
}

\author{
Ameer L. Saleh \\ Maab A. Hussain \\ Sahar M.Klim \\ Department of Electrical Engineering, College of Engineering, University of Misan \\ The_prince377@yahoo.com maab_alaa@yahoo.com saharmahdie@yahoo.com
}

\begin{abstract}
This paper present an optimal Fractional Order PID (FOPID) controller based on Particle Swarm Optimization (PSO) for controlling the trajectory tracking of Wheeled Mobile Robot(WMR).The issue of trajectory tracking with given a desired reference velocity is minimized to get the distance and deviation angle equal to zero, to realize the objective of trajectory tracking a two FOPID controllers are used for velocity control and azimuth control to implement the trajectory tracking control. A path planning and path tracking methodologies are used to give different desired tracking trajectories. PSO algorithm is using to find the optimal parameters of FOPID controllers. The kinematic and dynamic models of wheeled mobile robot for desired trajectory tracking with PSO algorithm are simulated in Simulink-Matlab. Simulation results show that the optimal FOPID controllers are more effective and has better dynamic performance than the conventional methods.
\end{abstract}

Keyword: Mobile robot, Modeling and Simulation, Trajectory Tracking Techniques, PSO Algorithm, Fractional Order PID Controller.

يقدم هذا البحث، المنحكم التتاسبي التكاملي التفاضلي الكسري الامتل اعتمادا على خوارزمية اسراب الطيور للسيطرة

على تتبع المسار للانسان الالي ذو العجلات. حيث يتم تقليل مثكلة تتبع المسار مع إعطاء السر عة المرجعية المطلوبة للحصول

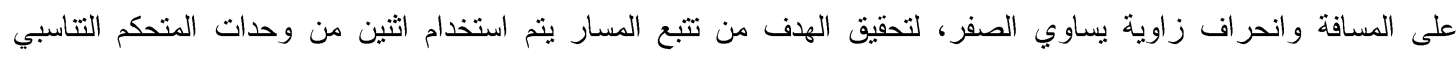

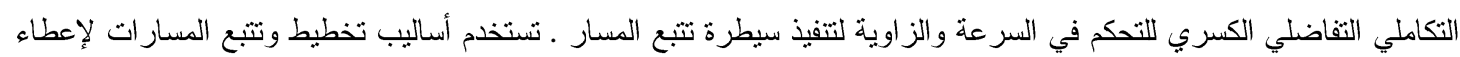

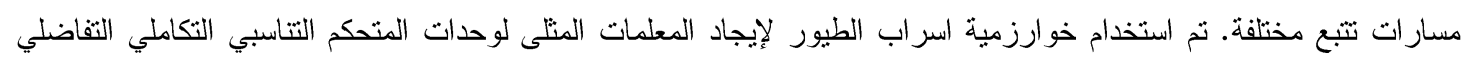

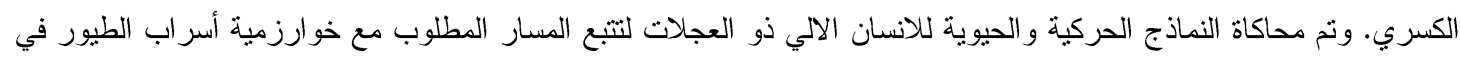

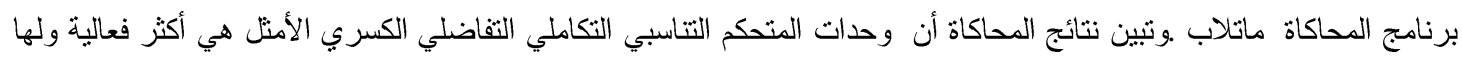
أداء ديناميكي أفضل من الطرق التقليدية.

الكلمات المفتاحيه: الانسان الالي، الندذجة والمحاكاة، تقنيات تتبع المسار ، خوارزمية اسراب الطيور، المتحكم التتاسبي النكاملي التفاضلي الكسري.

\section{Introduction:}

Nowadays, the Wheeled mobile robots have been widely used in many applications such as, industrial automation, in the dangerous areas and difficult to access such as space, warlike environments, chemical-waste cleaning and for individual utilization in the different service, etc.. Robotics is a very important field in science. Human beings have tried to build an autonomous robot from many years ago (Hussein, 2015; Dariusz, 2011).

The evolution of a new technology of human beings becomes factual. Robotics attracts common people and not only those educated in this field. The constructed robots are more and more complex. They become independent system because they 
are equipped with built-in computers. Lego Mindstorms NXT is a good example about a robot which contain ingenuity of engineers from the MIT Media Lab. The young designers use more advanced technologies and build more complex robots. The wheeled mobile robots are the most popular designs(Dariusz,2011).

There are two categories for a robot which are platform robots and mobile robots. The platform robot is mounted on a one physical location and materials transport to the platform near the robot. The platform robot is usually utilized in car factories, for welding or stamping which means that is used in mass production. Mobile robots are not fixed in one location and they have the ability to move around in their environment; therefore, this type of mobile robots can be described as a motion device that execute automated assignments, by using artificial intelligence (AI) techniques, depending on the human orientation or a specific program. Mobile robots also divided into wheeled, tracked or legged robots, and they are more useful than platform robots(Ahmed, 2012).

Robotic systems possess nonholonomic behavior which makes them particularly interesting and searchable because the most mobile robots are nonholonomic wheeled mechanical systems which is caused difficult control on on the movement of the wheeled that has three degrees of flexibility for control of the mobile robot, just two control motions under the nonholonomic kinematics (Khulood, 2014).

In general, the mobile robots navigation control issues can be ordered into three classifications: The first classification is the position estimation of the robot in its working environment is one of the significant problems with mobile robots which can be solved by using its on-board sensors with dynamic condition changes. The second classification is trajectory planning and generation. The trajectory planning is executed by utilizing certain optimization techniques with taking parameters other than the robot's dynamics and kinematics into consideration. The third classification is designing and implementing the navigation control system so that the mobile robot must be able to track it to get the desired trajectory with high accuracy and minimum error (Ahmed, 2012; Khulood , 2014).

The mobile robots have various behaviors that could be modeled path planning, path following, Trajectory(path) tracking, adaptive goal seeking. The path tracking control of mobile robot is an essential part of modern robots. The main task for any mobile robots is to move on a specific path. In recent years, many researchers have been dealing with researches that concern with control techniques to control path tracking. Furthermore, Many controlling techniques have been utilized, for example, sliding mode control, back stepping technique, adaptive control, fuzzy control, and neural network control, etc..(Ahmed, 2012).

This paper describes first the dynamic and kinematic model which used to simulate the movement of the mobile robot in an environment with used path planning and path tracking methodology to calculate the distance and the angle that has to be covered in order to meet the destination.

In paper present an effective and more important controller based on Fractional Order PID (FOPID) controller is used for controlling the wheeled mobile robot. The PSO algorithm used for numerical calculation of optimal FOPID controller gains which is used to adjust the linear velocity and the azimuth for the wheeled mobile robot and give better performance. 


\section{Modeling of Mobile Robot:}

The modeling of the mobile robot can be described in kinematic and dynamic model. The model deals with the geometrical relations that studies the mathematics of motion and dominate the system with taking into consideration effect the kinematics and dynamic forces.

\section{A. Kinematic Model:}

This model studies the mathematics of motion regardless of the forces that affect the motion. It is dealing with the geometrical relations that dominate the system, and also deals with the relationship between the motion of a system and the control parameters (Turki, 2013).

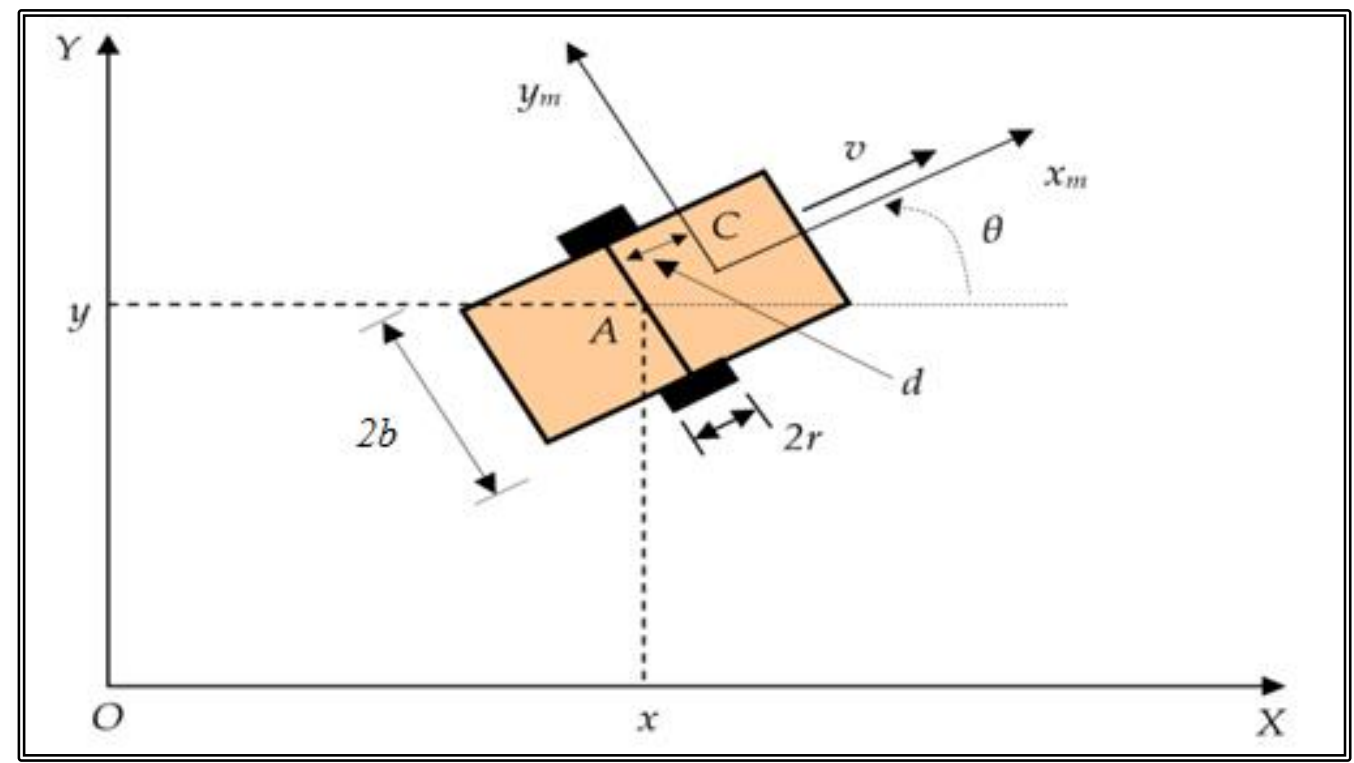

Figure1: anonholonomic mobile robot.

Figure (1) demonstrates the kinematics planner of a two wheel mobile robot. Where the global coordinate represented in $(\mathrm{O}, \mathrm{X}, \mathrm{Y}), \mathrm{v}$ is the robot velocity, w the robot angular velocity, $\mathrm{v}_{\mathrm{l}}$ the left driving wheel velocity, $\mathrm{v}_{\mathrm{r}}$ the right driving wheel velocity, $2 b$ the space between the two driving wheels, $r$ the driving wheels radius, the position of the robot represented by $\mathrm{x}$ and $\mathrm{y}$, and finally the orientation of the robot represented by $\theta$. Equations $(1,2)$ represent the motion differential drive for a two wheel mobile robot (Turki, 2013; Peter, 2011).

$\mathrm{v}_{\mathrm{l}}=\mathrm{w}_{\mathrm{l}} \mathrm{r}$

$\mathrm{v}_{\mathrm{r}}=\mathrm{w}_{\mathrm{r}} \mathrm{r}$

Where $w_{1}$ and $w_{r}$ are angular velocities of the left and right driving wheels respectively(Jinzhu, 2007).

The nonholonomic limitation equation of the robot is as follows:

$\dot{\mathrm{x}} \sin \theta-\dot{\mathrm{y}} \cos \theta=0$ 
From the above equations the following equations obtained:

$\mathrm{v}=\frac{\mathrm{w}_{\mathrm{r}}+\mathrm{w}_{\mathrm{l}}}{2} \mathrm{r}, \quad \mathrm{w}=\frac{\mathrm{w}_{\mathrm{r}}-\mathrm{w}_{\mathrm{l}}}{2 \mathrm{~b}} \mathrm{r}$

Equation (5) defined the dynamic function of the robot:

$\dot{\mathrm{x}}=\mathrm{v} \cos \theta, \quad \dot{\mathrm{y}}=\mathrm{v} \sin \theta, \quad \dot{\theta}=\mathrm{w}$

The combination of the latest two equations will produce the following:

$\left[\begin{array}{c}\dot{x} \\ \dot{y} \\ \dot{\theta}\end{array}\right]=\left[\begin{array}{ll}\frac{r}{2} \cos \theta & \frac{r}{2} \cos \theta \\ \frac{r}{2} \sin \theta & \frac{r}{2} \sin \theta \\ -\frac{r}{2 b} & \frac{r}{2 b}\end{array}\right]\left[\begin{array}{l}\mathrm{w}_{\mathrm{l}} \\ \mathrm{w}_{\mathrm{r}}\end{array}\right]$

Accordingly, equation (6) should be separated. Where $\theta$ is just related to $\omega, \mathrm{x}$ and $y$ are just related only to $v$. So, the kinematics model of the:

$\left[\begin{array}{l}\dot{x} \\ \dot{y} \\ \dot{\theta}\end{array}\right]=\left[\begin{array}{ll}\cos \theta & 0 \\ \sin \theta & 0 \\ 0 & 1\end{array}\right]\left[\begin{array}{c}\mathrm{v} \\ \mathrm{w}\end{array}\right]$

Where $\dot{x}$ and $y$ represent the robot velocity in the direction of X-axis and Yaxis, respectively, $\mathrm{V}$ represent the robot linear velocity, $\theta^{\prime}$ represent the robot rotational velocity. Therefore, the kinematics model of the robot can be represented by the following matrix:

$\left[\begin{array}{l}\mathrm{V} \\ \dot{\theta}\end{array}\right]=\left[\begin{array}{lc}\mathrm{r} / 2 & \mathrm{r} / 2 \\ \mathrm{r} / 2 \mathrm{~b} & -\mathrm{r} / 2 \mathrm{~b}\end{array}\right]\left[\begin{array}{l}\mathrm{w}_{\mathrm{r}} \\ \mathrm{w}_{\mathrm{l}}\end{array}\right]$

\section{B.Dynamics of A Mobile Robot}

The dynamic model is acquired from the physical laws that govern the robot subsystems which including the electric and mechanical forces, friction and robot mechanism.

In this paper, a dynamic model of the robot will be derived according to a nonholonomic robot scheme is shown in fig. 1 . The position of the mass center of the robot can be used to define the robot position in the absolute coordinate system $\{\mathrm{X}, \mathrm{O}, \mathrm{Y}\}$. The equations of kinematic mobile robot can be described from fig.(1) as follows (Turki, 2013; Jinzhu, 2007; Gokhan , 2008):

$\mathrm{I}_{\mathrm{v}} \ddot{\varphi}=\mathrm{D}_{\mathrm{r}} \mathrm{l}-\mathrm{D}_{\mathrm{l}} \mathrm{l}$

$\mathrm{M} \dot{\mathrm{v}}=\mathrm{D}_{\mathrm{r}}+\mathrm{D}_{\mathrm{l}}$

$\mathrm{I}_{\mathrm{w}} \ddot{\varphi}_{\mathrm{i}}+\mathrm{c} \dot{\varphi}_{\mathrm{i}}=\mathrm{ku}_{\mathrm{i}}-\mathrm{rD}_{\mathrm{i}} \quad(\mathrm{i}=\mathrm{r}, \mathrm{l})$

Where $\varphi$ the Azimuth of robot, $\mathrm{I}_{\mathrm{V}}$ Moment of inertia around the C.G. of robot, $D_{r}$ and $D_{1}$ are the forces for right and left driving, respectively; 1 is the distance between left and right wheel; $M$ is the robot mass, $v$ the robot velocity, $\mathrm{I}_{\mathrm{w}}$ the 
moment of inertia of wheel, $\mathrm{c}$ the viscous friction factor, $\mathrm{k}$ the driving gain factor, $\mathrm{u}_{\mathrm{i}}$ is the driving input, $\mathrm{r}$ the radius of wheel.

further, the geometrical relationships between the three variables $\varphi, v, \theta$. Given by:

$\mathrm{r} \dot{\theta}_{\mathrm{r}}=\mathrm{v}-\mathrm{l} \dot{\varphi}$

$\mathrm{r} \dot{\theta}_{\mathrm{l}}=\mathrm{v}-\mathrm{l} \dot{\varphi}$

The mathematical model for the dynamic part of mobile robot can be described in state space. Where the state variables for the robot is defined as $X=[\varphi$, $\mathrm{v}, \theta]$, the manipulated inputs variable as $\mathrm{u}=\left[\mathrm{u}_{\mathrm{r}}, \mathrm{u}_{\mathrm{l}}\right]$ and the output variable as $\mathrm{y}=[\mathrm{v}$, $\theta]$. Then:

$\dot{\mathrm{x}}=\mathrm{Ax}+\mathrm{Bu}$

$\mathrm{y}=\mathrm{Cx}$

Where:

$$
\begin{array}{ccc}
\mathrm{A}=\left[\begin{array}{ccc}
a_{1} & 0 & 0 \\
0 & 0 & 1 \\
0 & 0 & a_{2}
\end{array}\right], & \mathrm{B}=\left[\begin{array}{cc}
\mathrm{b}_{1} & \mathrm{~b}_{1} \\
0 & 0 \\
\mathrm{~b}_{2} & -\mathrm{b}_{2}
\end{array}\right], & \mathrm{C}=\left[\begin{array}{ccc}
1 & 0 & 0 \\
0 & 1 & 0
\end{array}\right] \\
\mathrm{a}_{1}=\frac{-2 \mathrm{c}}{\left(\mathrm{Mr}^{2}+2 \mathrm{I}_{\mathrm{w}}\right)}, & \mathrm{a}_{2}=\frac{-2 \mathrm{cl}^{2}}{\left(\mathrm{I}_{\mathrm{v}} \mathrm{r}^{2}+2 \mathrm{I}_{\mathrm{w}} \mathrm{l}^{2}\right)} \\
\mathrm{b}_{1}=\frac{\mathrm{kr}}{\left(\mathrm{Mr}^{2}+2 \mathrm{I}_{\mathrm{w}}\right)}, & \mathrm{b}_{2}=\frac{-\mathrm{krl}}{\left(\mathrm{I}_{\mathrm{v}} \mathrm{r}^{2}+2 \mathrm{I}_{\mathrm{w}} \mathrm{l}^{2}\right)}
\end{array}
$$

The following equations (16) and (17) represent the relation between the input torques to the $\operatorname{robot}\left(\mathrm{u}_{\mathrm{r}}\right.$ and $\left.\mathrm{u}_{\mathrm{l}}\right)$ and the output of the controller $\left(\mathrm{u}_{\mathrm{v}}\right.$ and $\left.\mathrm{u}_{\varphi}\right)$ :

$$
\begin{aligned}
& \mathrm{u}_{\mathrm{r}}=\mathrm{u}_{\mathrm{v}}+\mathrm{u}_{\varphi} \\
& \mathrm{u}_{\mathrm{l}}=\mathrm{u}_{\mathrm{v}}-\mathrm{u}_{\varphi}
\end{aligned}
$$

Where $u_{v}$ is the torque required for controlling the velocity of robot and $u_{\varphi}$ is the torque required for controlling the robot's azimuth.

\section{Navigation of a Mobile Robot}

Navigation of a mobile robot in a unclear and undefined environment which is represented a worry for the mobile robot due to various obstacles that mobile robots faced it in his path which have to be detected and avoided without any colliding. Navigation of the mobile robots can be developed by utilizing intelligent systems with optimization techniques. The navigation problem control of mobile robots is classified to three possible motion tasks as follows (Ahmed, 2012): 


\section{A.Path Tracking(Trajectory Tracking)}

Trajectory tracking is a major part for mobile robots. The essential mission for the mobile robots is moving along a predefined path and takes a decision where to go and that information is taken by a reference path or leader robot, whereas trajectory tracking would be zero when the mobile robot would be at rest. In the last decade, a lot of researches are interested in the trajectory tracking control of mobile robots. It refers to the case where a robot has to trajectory the path according to a time reference(Jinzhu , 2007). In the trajectory tracking control system the velocity error $e_{v}$ and the azimuth error $e_{\theta}$ are represented as the inputs while the developing torque desired for driving the wheels $u_{r}$ and $u_{1}$ are represented as the output. The following equations represent input deviation $\mathrm{e}_{\mathrm{v}}$ and $\mathrm{e}_{\varphi}$ :

$\mathrm{e}_{\mathrm{v}}=\mathrm{v}_{\mathrm{d}}-\mathrm{v}$

$\mathrm{e}_{\varphi}=\varphi_{\mathrm{d}}-\varphi$

Where $\mathrm{v}_{\mathrm{d}}$, represents the desire velocity, $\varphi_{\mathrm{d}}$ is the reference azimuth, $\mathrm{v}$ is the actual linear velocity, and $\varphi$ the azimuth of the mobile robot.

\section{B. Path Planning:}

Path planning is an essential mission in computational intelligence theory of a mobile robot. The path can be generated between two points with taking parameters other than robot's dynamics and kinematics into consideration. In addition, choosing a path free from obstacles in the real environment and training it to face some obstacles. The path would be planning motion of a system to achieve a goal, this would have value even for a system at rest.

The problem deals with finding the path towards the given goal. The problem becomes even more complex if the robot needs to find an optimal path given some constraints like shortest path or minimum time or even minimization of energy (Jinzhu , 2007). First step, the mobile robot can move towards the desired point since it knows initial and final point. The distance between robot and its goal is (Emina, 2016; Buniyamin, 2011; Thoa, 2016):

$\mathrm{d}=\sqrt{\left(\mathrm{y}_{\text {target }}-\mathrm{y}_{\text {robot }}\right)^{2}+\left(\mathrm{x}_{\text {target }}-\mathrm{x}_{\text {robot }}\right)^{2}}$

Deviation angle we get from:

$\varphi=\tan ^{-1} \frac{\mathrm{y}_{\text {target }}-\mathrm{y}_{\text {robot }}}{\mathrm{x}_{\text {target }}-\mathrm{x}_{\text {robot }}}$

Considering that $\varphi$ is the desired angle associated with the straight distance from the current position towards the target.

\section{Obstacle Avoidance}

In the autonomous mobile robots, the workspace of the robot is free and must be avoid the collision. Where the robot moves at a certain velocity then decreased it near the final point and stop there. Where the portable sensors on the robot gives an 
indication of the presence of obstacles nearby, the robot must reduce the velocity and change the angle to avoid the obstacle(Thoa, 2016).

\section{Fractional Order PID $\left(\mathrm{PI}^{\lambda} \mathrm{D}^{\mu}\right)$ Controller}

In the integer PID controller, the real order for the derivation and integration that we want to control are both unity. But in fractional-order PID controllers, a fractional order was used in the integration and differentiation parts of this controller to improve the conventional PID controller(Buniyamin, 2011). The $\mathrm{P} \mathrm{I}^{\lambda} \mathrm{D}^{\mu}$, is an expansion of traditional PID controller with a new integral order $\lambda$ and a new derivative order $\mu$ have fractional values that let the system less sensitive to the change in parameters and better control of dynamic systems (Ameer, 2014; Mouwafak, 2014). The differential equation of the $\mathrm{PI}^{\lambda} \mathrm{D}^{\mu}$ controller can be represented as follows:

$$
u(t)=K_{p} e(t)+K_{i} D^{-\lambda} e(t)+K_{d} D^{\mu} e(t)
$$

where $\mathrm{e}(\mathrm{t})$ : the error between the actual output and a desired set point; $\mathrm{u}(\mathrm{t})$ : the control output; Thus the transfer laplace function of this controller becomes:

$\mathrm{G}(\mathrm{s})=\mathrm{K}_{\mathrm{p}}+\mathrm{K}_{\mathrm{i}} \mathrm{S}^{-\lambda}+\mathrm{K}_{\mathrm{d}} \mathrm{S}^{\mu}$

The structure of FOPID controller is shown in Figure.2. The conventional PID can be generated by selecting $\lambda=1, \mu=1$. Moreover, Using $\lambda=0, \mu=1$ and $\lambda=$ $1, \mu=0$ respectively, will produce the classical PD \& PI controllers as shown in Fig.3. From equations $(14,15)$ can see the FOPID controller has five control parameters $\left(\mathrm{K}_{\mathrm{p}}, \mathrm{K}_{\mathrm{i}}, \mathrm{K}_{\mathrm{d}}, \lambda\right.$, and $\left.\mu\right)$ that need tuning to obtain a robust controller with more flexibility and increase in the accurate of the system with better performance.

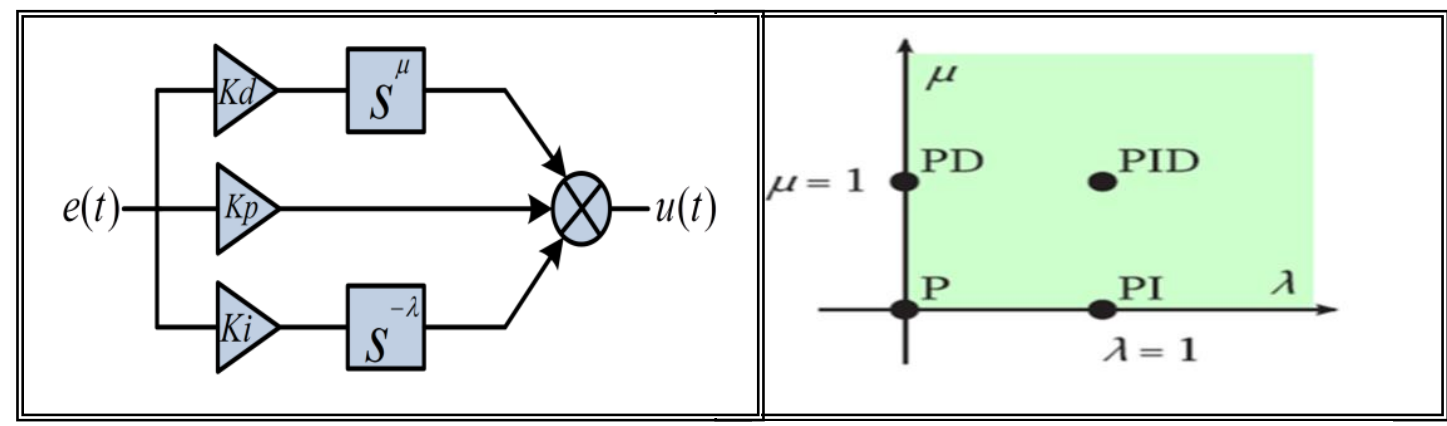

Figure2: Fractional order PID controller.

Figure3: Generalized FOPID controller.

\section{Particle Swarm Optimization}

PSO is a stochastic optimization technique which derived from the principle of collective behavior of animals (bird flocks, fish pools) during their search on food. PSO algorithm is one of the computational methods used to solve optimization problems. In this algorithm, each individual solution is called a particle. Every particle has an initial velocity which is flowing in the search space with dimensions the problem(Adel, 2014).Each particle saved own previous experience and experience of neighboring particles in its swarm to select the best position for itself which called 
the personal best position(called the Pbest). When a particle in the whole swarm have the best position in the swarm which is called the global best position(gbest).Where the best previous position of any particle is called local best position (lbest). The performance of each particle to decide whether the best solution is accomplished according to the objective function(Jun-Yi,2006).

The objective functions investigated are based on the desired criterion. The most common performance standards are based on the error criterion such as Integrated Absolute Error (IAE), Integrated of Time weight Square Error (ITSE) and Integrated of Error Square (ISE) (Adel, 2014). A selection of these criteria depends on both system and controller. The velocity and position of each particle in the swarm are updated by using the following equations:

$$
\begin{gathered}
\mathrm{v}_{\mathrm{i}}^{\mathrm{k}+1}=\mathrm{w} * \mathrm{v}_{\mathrm{i}}^{\mathrm{k}}+\mathrm{c}_{1} * \mathrm{R}_{1} *\left(\text { lbest }_{\mathrm{i}}-\mathrm{x}_{\mathrm{i}}^{\mathrm{k}}\right)+\mathrm{c}_{2} * \mathrm{R}_{1} \\
*\left(\text { gbest }_{\mathrm{i}}-\mathrm{x}_{\mathrm{i}}^{\mathrm{k}}\right) \\
\mathrm{x}_{\mathrm{i}}^{\mathrm{k}+1}=\mathrm{x}_{\mathrm{i}}^{\mathrm{k}}+\mathrm{v}_{\mathrm{i}}^{\mathrm{k}+1}
\end{gathered}
$$

Where: $x_{i}^{k}$ is the instant position of particle $i$ at iteration $k ; v_{i}^{k}$ is the speed of particle $\mathrm{i}$ at iteration $\mathrm{k} ; \mathrm{c}_{1}$ andc $\mathrm{c}_{2}$ are the acceleration constants; $\mathrm{R}_{1}, \mathrm{R}_{2}$ are a random variables between 0 and 1 .

In this paper, an Integral of Squared Error (ISE) objective function isused to find the optimal solution with a minimum velocity and azimuth error. The cost fitness is evaluated as follows:

fitness function $=\min ($ ISE $)$

where:

$\operatorname{ISE}=\int \mathrm{e}^{2}(\mathrm{t}) \mathrm{dt}$

$\mathrm{e}(\mathrm{t})=e \mathrm{v}^{2}(\mathrm{t})+\mathrm{e} \theta^{2}(\mathrm{t})$

In PSO algorithm, each particle parameter is initiated to create a population and then complete the algorithm as in flowchart in fig.(4) which involves adjusting the parameters FOPID controller for, to ensure the minimization of objective function. 


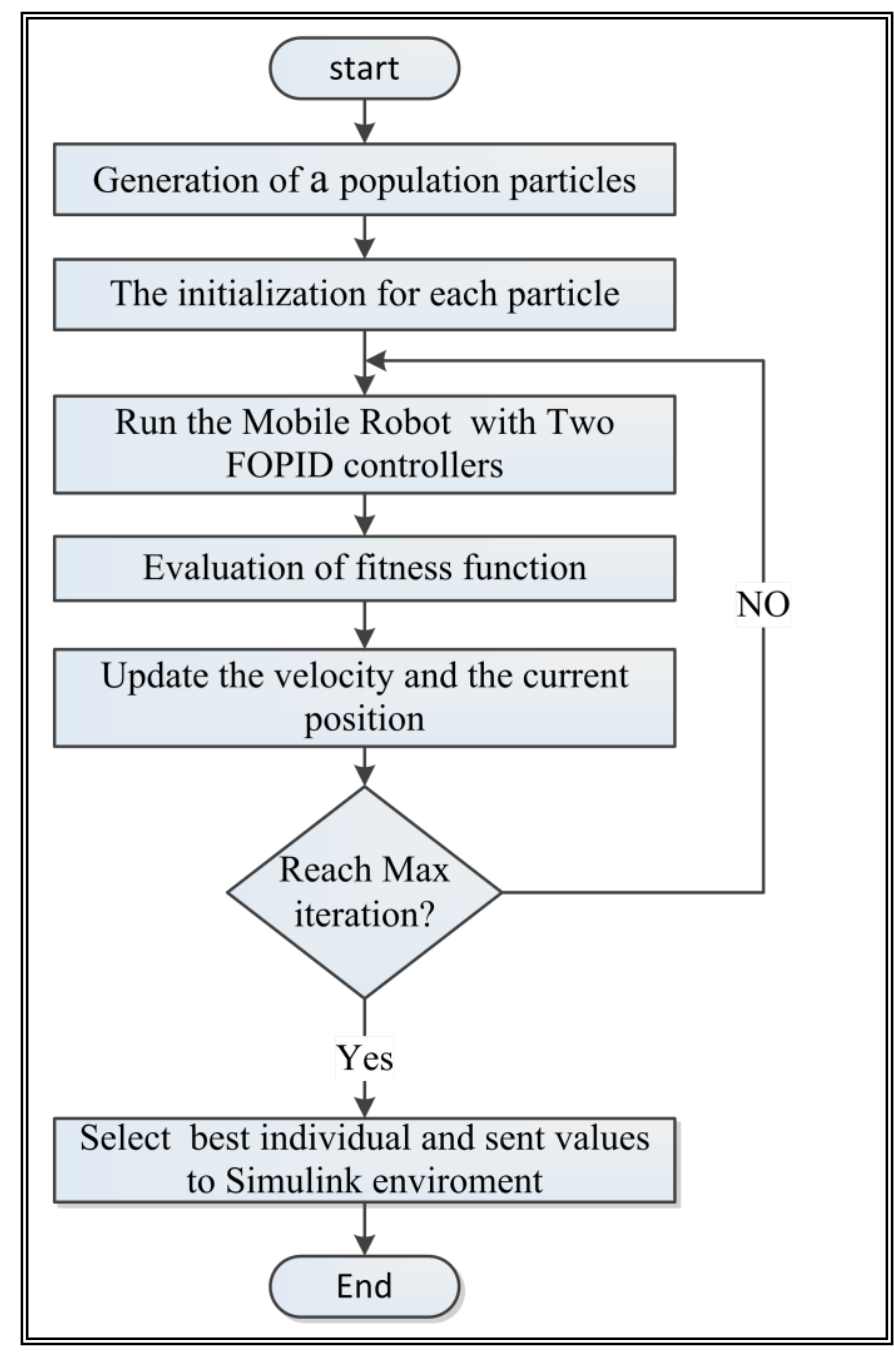

Figure(4): Flowchart of PSO.

\section{Design and Simulink Implementation of Path Planning and Path Tracking for Mobile Robot Using FOPID Controller}

The dynamic and kinematic model of a mobile robot represented according to the equations[1-17], while the trajectory tracking and path planning represented according to the equations[18-21] respectively. Figure(5) shows the overall block diagram of mobile robot with trajectory tracking control system. In this paper, a FOPID controller used to ensure that the mobile robot can track target trajectory. Two FOPID controllers are used for motion control of mobile robot. The first one of FOPID controller is used to control the velocity and another for controlling azimuth of the mobile robot.To optimize the parameters of FOPID controller, PSO algorithm is used to give better performance according to the cost function. The PSO algorithm contents are given in Table(1). Figure (6) shows the complete Simulink model of the mobile robot control system with two FOPID controllers. The path planning of Navigation of a mobile robot is shown in fig.(7). 
Journal of University of Babylon, Engineering Sciences, Vol.(26), No.(4): 2018.

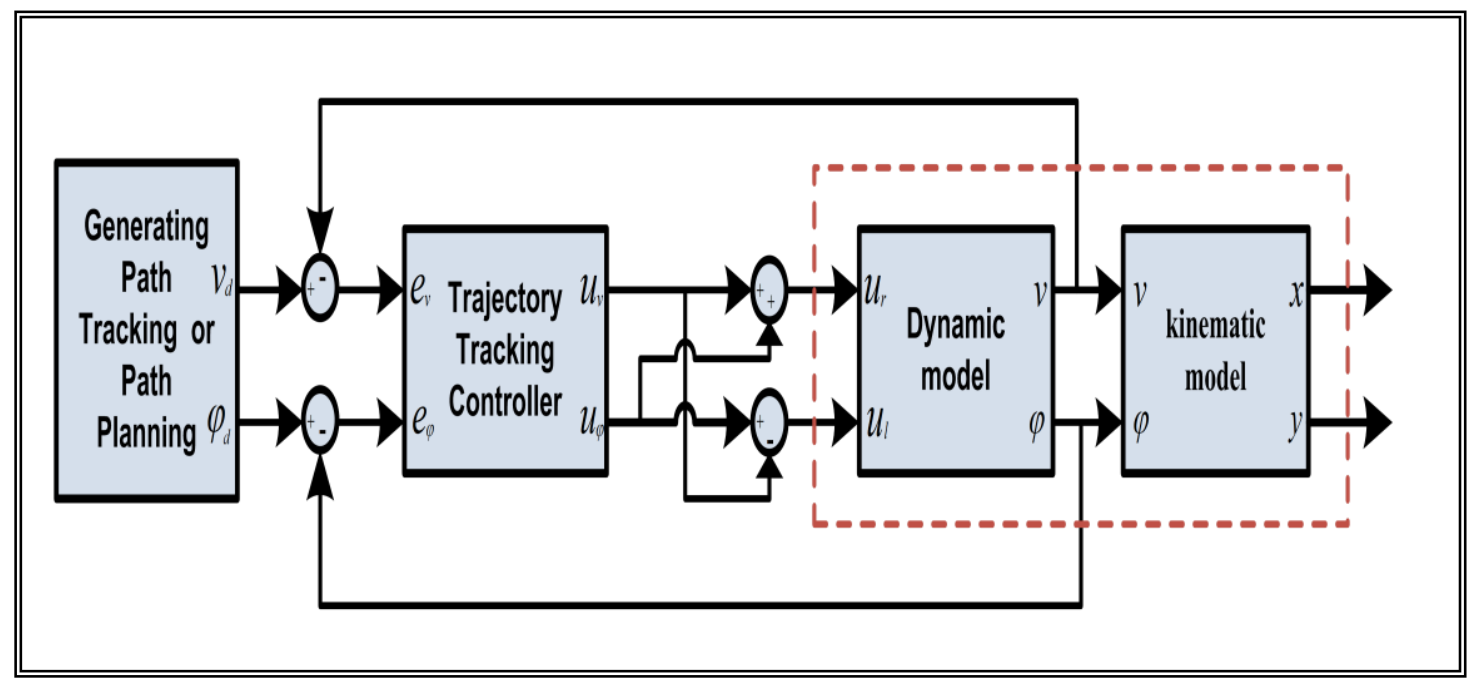

Figure 5: Overall block diagram of mobile robot with trajectory tracking control system.

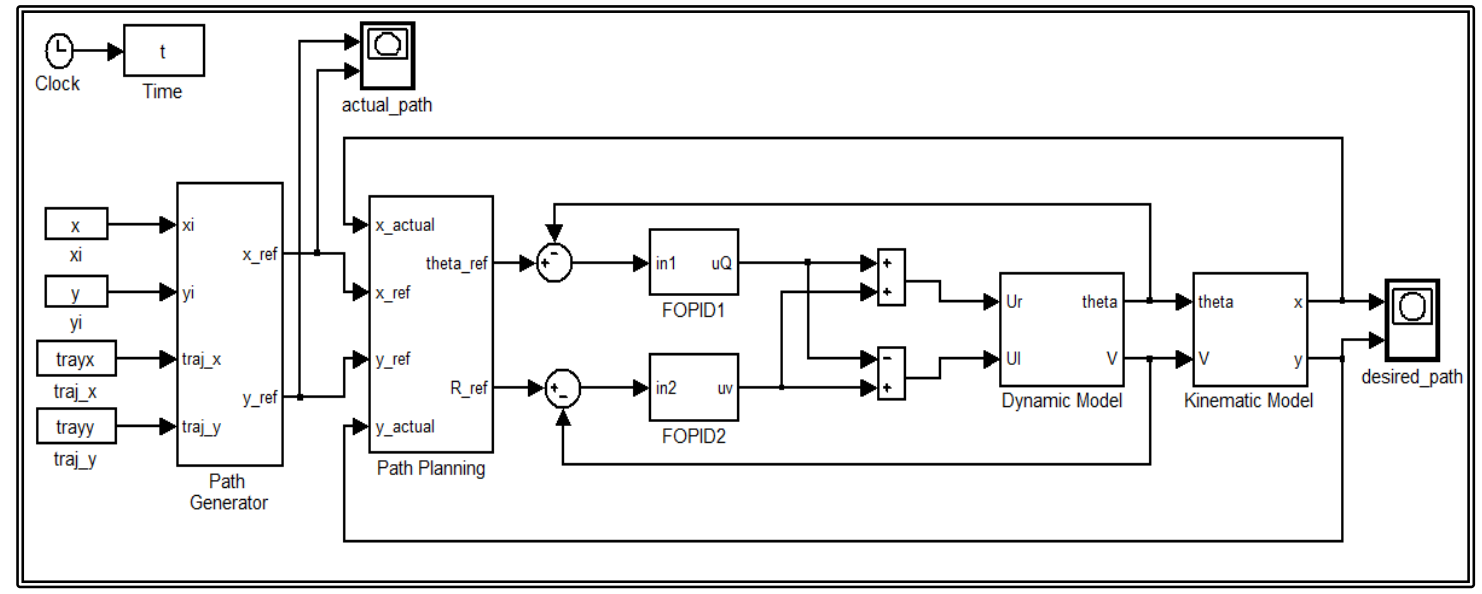

Figure (6): The Overall Simulink model of the mobile robot with trajectory tracking control system using Two FOPID controllers.

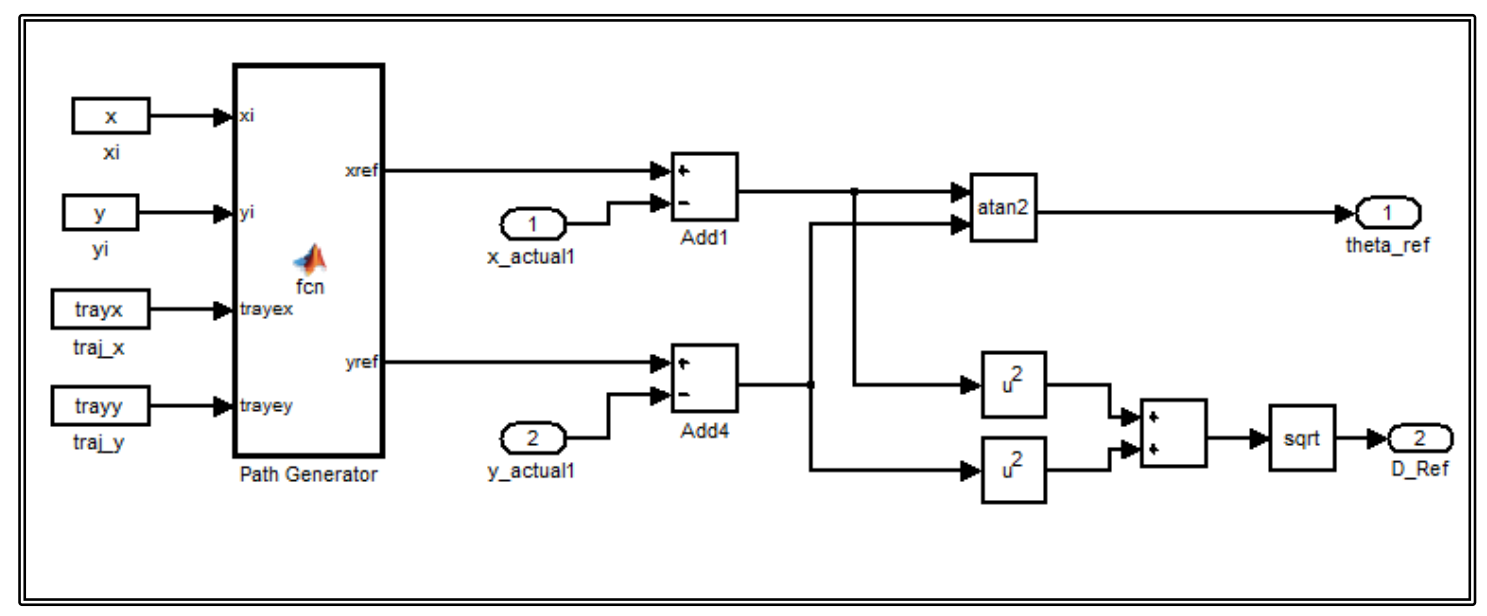

Figure(7): Path planning of Navigation for a mobile robot. 
Journal of University of Babylon, Engineering Sciences, Vol.(26), No.(4): 2018.

Table1: The PSO algorithm contents

\begin{tabular}{|c|c|}
\hline PSO_Parameter & Value \\
\hline No of birds(swarm) & 40 \\
\hline $\begin{array}{c}\text { Maximum iteration } \\
\text { number }\end{array}$ & 60 \\
\hline Dimension & 10 \\
\hline PSO parameter $\left(\mathrm{c}_{1}, \mathrm{c}_{2}\right)$ & $1,1.3$ \\
\hline $\mathrm{w}_{\max }, \mathrm{w}_{\min }$ & $0.9,0.3$ \\
\hline
\end{tabular}

\section{Simulation Results}

The overall model of mobile robot with trajectory tracking control system and PSO algorithm is implemented in Simulink/Matlab program with sampling time $1 \mathrm{~ms}$.

The physical parameters of the mobile robot in the simulation are given (Altamiro, 2004): $\mathrm{M}=24 \mathrm{~kg}, \mathrm{I}_{\mathrm{V}}=0.4732 \mathrm{~kg} \cdot \mathrm{m}^{2}, \mathrm{I}_{\mathrm{W}}=0.0198 \mathrm{~kg} \cdot \mathrm{m}^{2}, \mathrm{l}=0.36 \mathrm{~m}$, $\mathrm{r}=0.057 \mathrm{~m}, \mathrm{c}=0.15833 \mathrm{~kg} / \mathrm{s}, \mathrm{k}=1.7$. Table(2) shows the optimization value for the parameters of the two FOPID using PSO. This paper has been solved two problems ofnavigation foe wheeled mobile robot. In each path planning and path tracking strategies using different shapes to investigation the goal of the FOPID controller with minimum error. The optimal parameters of two FOPID controllers is shown in Table(2).

\begin{tabular}{|c|c|c|c|c|c|c|c|c|c|c|}
\hline Constants & $\mathbf{K}_{\mathbf{p} 1}$ & $\mathbf{K}_{\mathbf{i} 1}$ & $\boldsymbol{\lambda}_{\mathbf{1}}$ & $\mathbf{K}_{\mathbf{d} \mathbf{1}}$ & $\boldsymbol{\mu}_{\mathbf{1}}$ & $\mathbf{K}_{\mathbf{p} \mathbf{2}}$ & $\mathbf{K}_{\mathbf{i} 2}$ & $\boldsymbol{\lambda}_{\mathbf{2}}$ & $\mathbf{K}_{\mathbf{d} \mathbf{2}}$ & $\boldsymbol{\mu}_{\mathbf{2}}$ \\
\hline Values & 5789 & 150 & 0.87 & 56 & 0.9 & 322.3 & 583 & 1.135 & 0.0001 & 0.8 \\
\hline
\end{tabular}

\section{A. Path Tracking}

In this strategy, a three trajectory shapes circular, linear and square are tested:

\section{1- Circular Trajectory:}

To test mobile robot for tracking circular path with desired linear velocity $\mathrm{v}_{\mathrm{d}}=$ $0.25[\mathrm{~m} / \mathrm{sec}]$ and desired azimuth given by:

$\theta_{\mathrm{d}}=(2 * 3.14 * \mathrm{f}(\mathrm{t}) / \mathrm{m}) \mathrm{rad}$, with $\mathrm{m}=-60$,

Where: $\mathrm{m}$ is the slop, $\mathrm{f}(\mathrm{t})=\mathrm{t}, 0 \leq \mathrm{t} \leq 60$ and $\mathrm{T}_{\mathrm{s}}=0.001 \mathrm{sec}$, ISE_ $\mathrm{v}=$ $1.3 * 10^{-3}$, ISE_ $\theta=1 * 10^{-3}$. The simulation result of the circular trajectory is shown in fig.(8). 


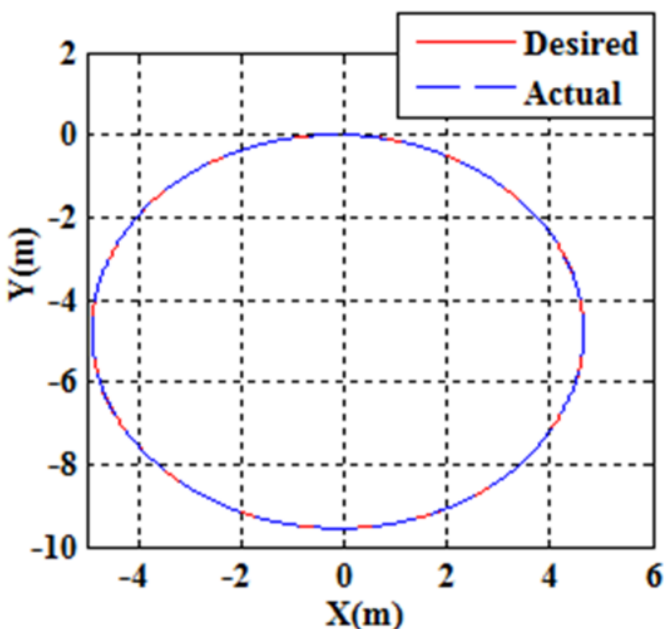

Figure(8): Circular path tracking.

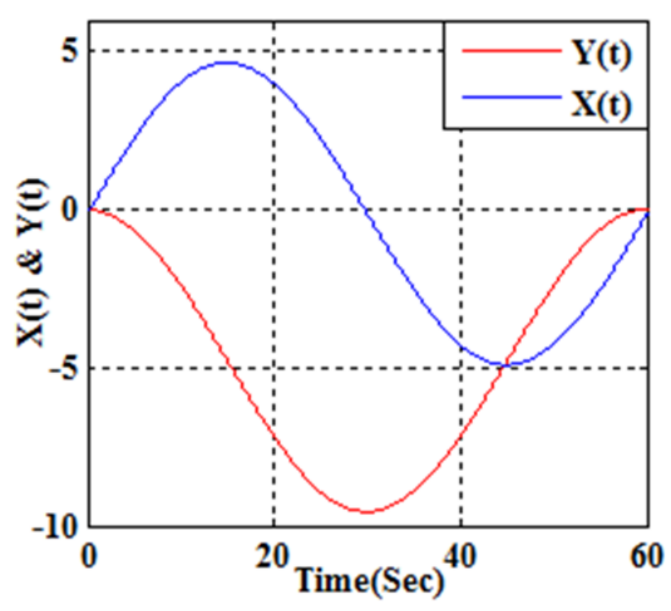

Figure(8-a): X\&Y for Circular path tracking.

\section{2- Linear Trajectory}

To test mobile robot for tracking Linear path with desired velocity $\mathrm{v}_{\mathrm{d}}=0.25$ $[\mathrm{m} / \mathrm{sec}]$ and desired azimuth given by:

$\theta_{\mathrm{d}}=(3.14 * \mathrm{f}(\mathrm{t}) / \mathrm{m}) \mathrm{rad}$, with $\mathrm{m}=6$

where: $\mathrm{m}$ is the slop $\mathrm{f}(\mathrm{t})=1$ and $0 \leq \mathrm{t} \leq 40, \mathrm{~T}_{\mathrm{s}}=0.001 \mathrm{sec}, \theta_{\mathrm{d}}=45^{\circ}$, ISE_ $\mathrm{v}=1^{*} 10^{-3}$,

ISE_ $\theta=4.5^{*} 10^{-3}$. The simulation result of the linear trajectory is shown in fig.(9).

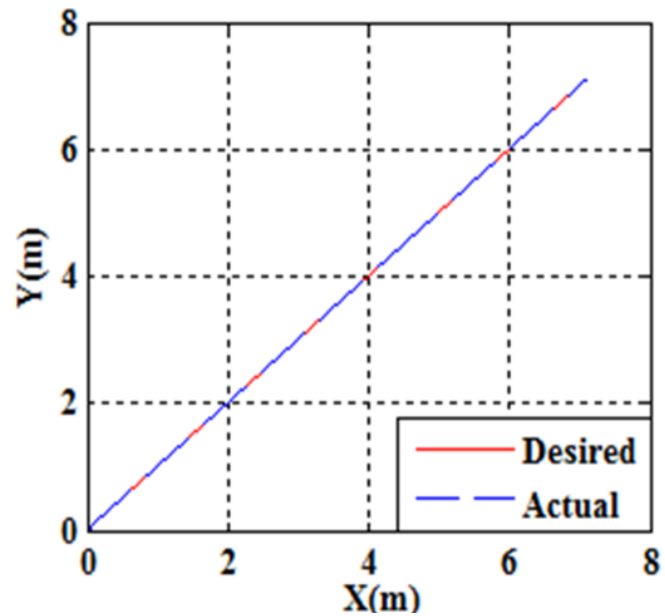

Figure(9): Linear path tracking.

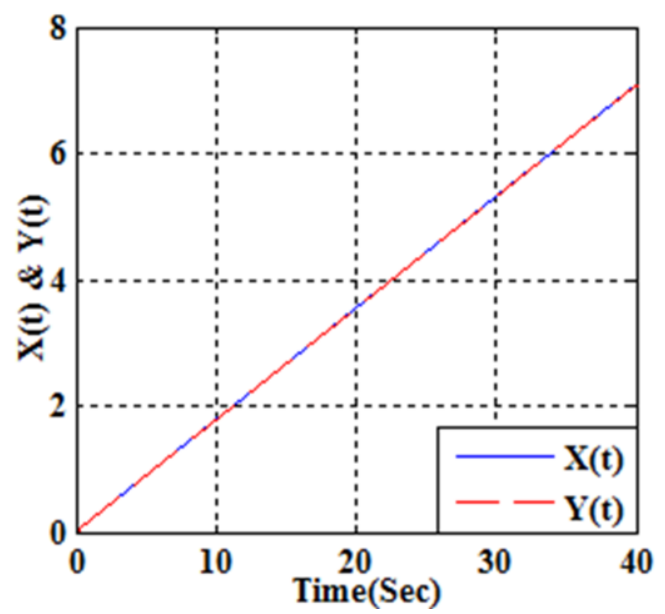

Figure(9-a): X\&Y for Linear path tracking.

\section{3- Sinusoidal Trajectory}

To test mobile robot for tracking square path with desired velocity $\mathrm{v}_{\mathrm{d}}=1$ $[\mathrm{m} / \mathrm{sec}]$ and desired azimuth given by:

$\theta_{\mathrm{d}}=\sin (t)$

Where: $0 \leq \mathrm{t} \leq 30, \mathrm{~T}_{\mathrm{s}}=0.001 \mathrm{sec}$, ISE_ $\mathrm{v}=1 * 10^{-3}$, ISE_ $\theta=0.8^{*} 10^{-3}$. The simulation result of the sinusoidal trajectory is shown in fig. (10). 


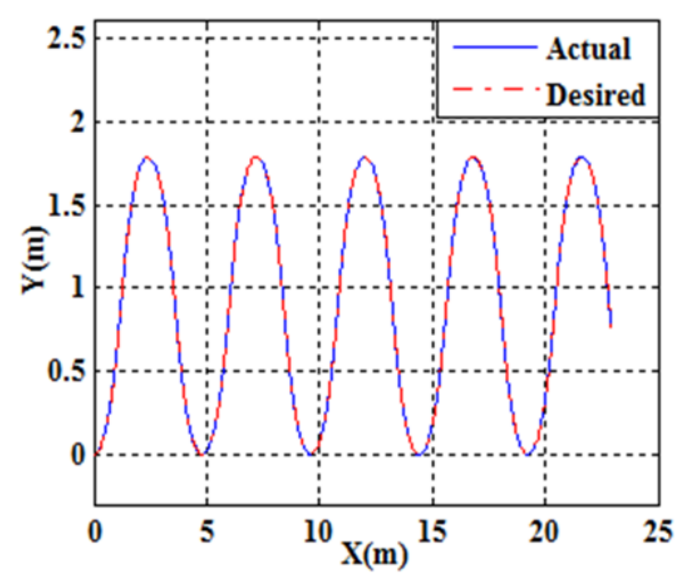

Figure(10): Square path tracking.

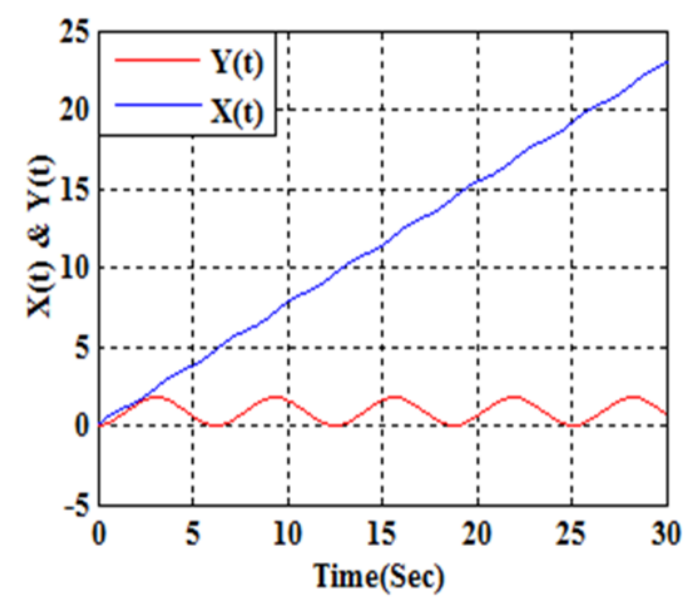

Figure(10-a): X\&Y for Square path tracking.

\section{B- Path Planning}

The path is a plan of geometric locus of the points in a given space where the robot has to pass through it. In this strategy, a two trajectory shapes bending and square are tested:

\section{1- Bending Trajectory:}

To test mobile robot for tracking Linear path with desired X\&Y which drawn in M-file and applied to the equations $(20,21)$ to give the required velocity and desired azimuth. Where: $0 \leq \mathrm{t} \leq 40, \mathrm{~T}_{\mathrm{s}}=0.001 \mathrm{sec}$ ISE_ $\mathrm{v}=1.15^{*} 10^{-3}$ and ISE_ $\theta=1 * 10^{-3}$. The simulation result of the bending trajectory is shown in fig.(11).

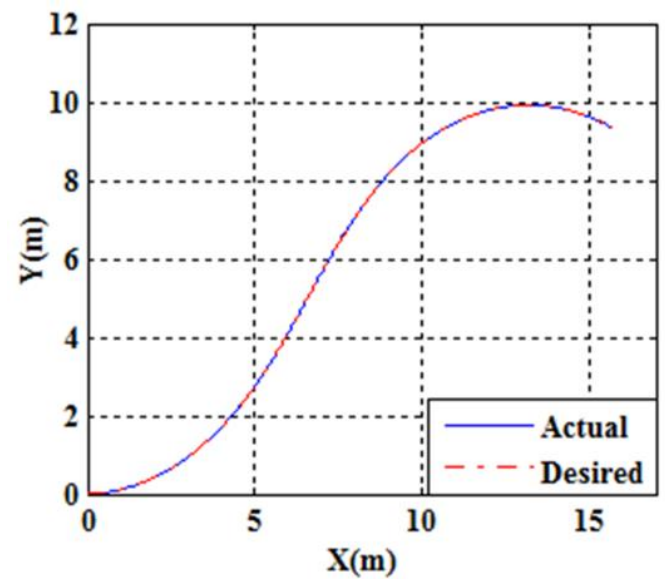

Figure(11): Bending path tracking.

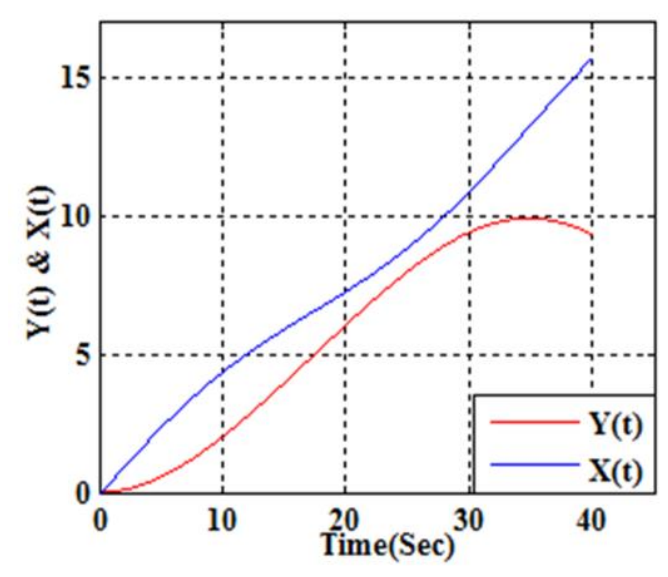

Figure(11-a): X\&Y for Bending path tracking.

\section{2- Square Trajectory}

To test mobile robot for tracking square path with desired $X \& Y$ which drawn in M-file and applied to the equations $(20,21)$ to give the required velocity and desired azimuth. Where $\mathrm{T}_{\mathrm{s}}=0.001 \mathrm{sec}, \mathrm{ISE}_{-} \mathrm{v}=1 * 10^{-3}$ and ISE_ $\theta=2.3$. The simulation result of the square trajectory is shown in fig.(12). 


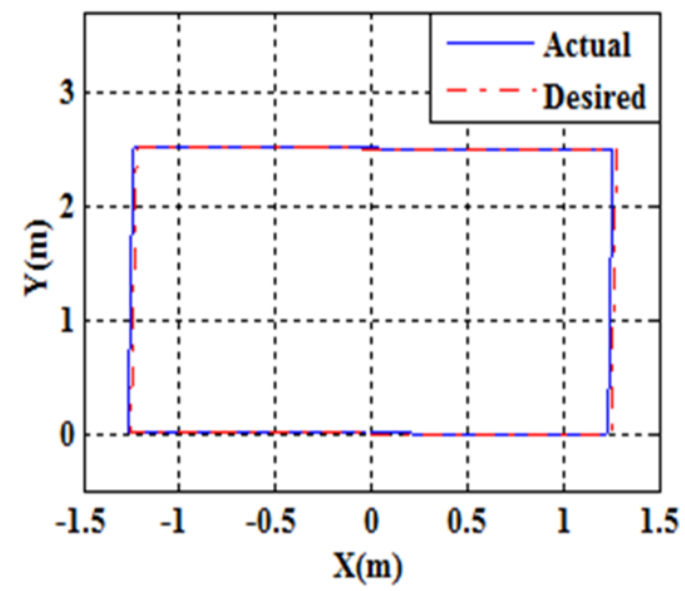

Figure(12): Square path tracking.

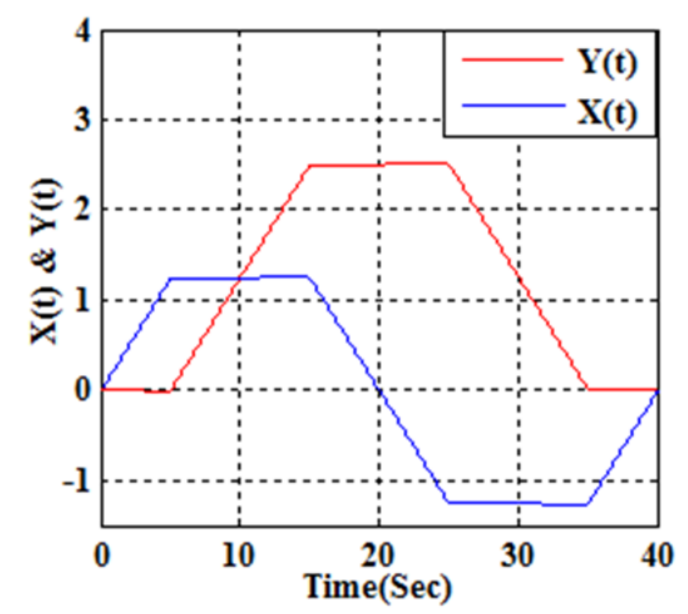

Figure(12-a): X\&Y for Square path tracking.

\section{Conclusion}

In this paper, The FOPID controller with PSO algorithm has been presented to overcome the problem of target trajectory tracking. A two strategies presents to get different desired tracking shapes. The path planning strategy is better than path tracking in the way of getting the path without obstacles. The PSO algorithm is used for tuning the parameters of FOPID controllers. The simulation results shows that this method is suitable to solve problem of target tracking with different shapes.

\section{References}

Adel A. Obed and Ameer L. Saleh, 2014, Speed Control of BLDC Motor Based on Recurrent Wavelet Neural Network, Iraq J. Electrical and Electronic Engineering, Vol.10 No.2.

Ahmed S. Al-Araji, 2012, Design of a Cognitive Neural Predictive Controller for

Altamiro V.Silveira and Elder M. Hemerly, 2004, CONTROL OF MOBILE ROBOTS VIA BIASED WAVELET NETWORKS, Learning and Nonlinear Models - Revista da Sociedade Brasileira de Redes Neurais, Vol. 2, No. 2 pp. 84-98.

Ameer L. Saleh and Adel A. Obed, 2014, Speed Control of Brushless DC Motor based on Fractional Order PID Controller, International Journal of Computer Applications (0975 - 8887) Volume 95- No.4, June.

Buniyamin N., Wan Ngah W.A.J., Sariff N., Mohamad Z., 2011, A Simple Local Path Planning Algorithm for Autonomous Mobile Robots, INTERNATIONAL JOURNAL OF SYSTEMS APPLICATIONS, ENGINEERING \& DEVELOPMENT, Issue 2, Volume 5.

Dariusz M. and Marcin P., 2011, Wheeled mobile robot modeling aspects, AGH University of Science and Technology.

Emina P., Saša P., Vlastimir N., Marko M., Ivan Ć., Boban R. and Miloš S., 2016, KINEMATIC MODEL AND CONTROL OF MOBILE ROBOT FOR TRAJECTORYTRACKING , ANNALS of Faculty Engineering Hunedoara International Journal of Engineering, Tome XIV [2016] - Fascicule 2 [May], ISSN: 1584-2665 [print; online], ISSN: 1584-2673 [CD-Rom; online]. 
GoKHAN BAYAR, E. İLHAN KONUKSEVEN, A. BUĞRA KOKU, 2008, Control of a Differentially Driven Mobile Robot Using Radial Basis Function Based Neural Networks , WSEAS TRANSACTIONS on SYSTEMS and CONTROL, ISSN: 1991-8763, Issue 12, Volume 3, December.

Hussein A. Lafta and Zainab F. Hassan, 2015, Mobile Robot Control Using Fuzzy Logic, Journal of Babylon University/Pure and Applied Sciences/ No.(2)/ Vol.(23): 2015.

Jinzhu P., Yaonan W.and Wei Sun, 2007, Trajectory-Tracking Control for Mobile Robot Using Recurrent Fuzzy Cerebellar Model Articulation Controller, Neural Information Processing - Letters and Reviews, Vol. 11, No. 1, January.

Jun-Yi Cao and Bing-Gang Cao, 2006, Design of Fractional Order Controller Based on Particle Swarm Optimization, Design of Fractional Order Controller Based on Particle Swarm Optimizati International Journal of Control, Automation, and Systems, vol. 4, no. 6, pp. 775-781, December.

Khulood E., Ahmed Al-Araj, 2014, Design of a Nonlinear PID Neural Trajectory Tracking Controller for Mobile Robot based on Optimization Algorithm, Eng. \& Tech Journal , Vol.32,Part (A), No.4.

Mobile Robot, PHD thesis.

Mouwafak A. Tawfik, Emad N. Abdulwahb and Salah M. Swadi, 2014, Trajectory Tracking Control for a Wheeled Mobile Robot Using Fractional Order PI $^{\mathrm{a}} \mathrm{D}^{\mathrm{b}}$ Controller, Al-Khwarizmi Engineering Journal, Vol. 10, No. 3, P.P. 39- 52.

Peter. , Anna J., 2011, Tracking Trajectory of the Mobile Robot Khepera II Using Approaches of Artifical Intelligence. Acta Electrotechnica et Informatica, Vol. 11, No. 1, 2011, 38-43.

Thoa T. Mac, Cosmin Copot, Robin De Keyser, Trung D. Tran , and Thich Vu, 2016, MIMO Fuzzy Control for Autonomous Mobile Robot, Journal of Automation and Control Engineering Vol. 4, No. 1, February.

Turki Y. Abdalla and Mustafa I. Hamzah, 2013, Trajectory Tracking Control for Mobile Robot using Wavelet Network, International Journal of Computer Applications (0975 - 8887) Volume 74- No.3, July. 